\title{
A indevida aplicação do enunciado de Súmula n. 281 do Tribunal de Contas da União e a proibição da participação de cooperativas de trabalho brasileiras em procedimentos licitatórios
}

\author{
The improper application of the statement of Precedent \\ no. 281 of the Federal Court of Accounts and the prohibition \\ on the participation of Brazilian labor cooperatives \\ in bidding procedures
}

Marianna Ferraz Teixeira ${ }^{1}$

Sumário: 1 Introdução. 2. O cooperativismo de trabalho. 3. A relação de trabalho. 3.1. Contrato de trabalho. 3.2. O ato cooperativo nas cooperativas de trabalho. 3.3. A terceirização do trabalho. 4. A terceirização na Administração Pública. 4.1. A licitação de serviços públicos. 4.2. Participação de cooperativas em licitações. 4.3. Súmula n. 281 do TCU. 5. Conclusão. Bibliografia.

Resumo: O presente trabalho busca analisar o enunciado de Súmula n. 281 do Tribunal de Contas da União, aprovada em 11 de julho de 2012, que veda a participação de cooperativas de trabalho em licitações quando o serviço a ser prestado exija a necessidade de subordinação, habitualidade e pessoalidade. Apesar das previsões da Lei de Licitações e da Lei de Cooperativas de Trabalho disporem que dito impedimento é proibido, muitos procedimentos licitatórios, em razão da súmula, excluem esse tipo societário da participação, o que faz com que princípios como o da legalidade e da igualdade

1 Advogada. Graduada em Direito e Especialista em Direito e Processo nos Tribunais pelo Centro Universitário de Brasília, MBA em Gestão em Cooperativas de Crédito na Universidade de São Paulo-ESALQ/USP. Mestranda em Gestão e Regime Jurídico-Empresarial da Economia Social ISCAP/Instituto Politécnico do Porto. Cursou Mestrado em Direito Tributário na Universidad Austral (Argentina). Membro do Instituto Brasileiro de Estudos em Cooperativismo-IBECOOP, da Comissão de Assuntos e Reforma Tributária e da Comissão de Direito Cooperativo da OAB/DF. Endereço: SRTVS Quadra 701, Bloco O, Ed. Novo Centro Multiempresarial, Sala 360, CEP: 70.340-000, Brasília/DF. E-mail: marianna@tfa.com.br. 
sejam violados, assim como afronta o preceito constitucional de fomento ao cooperativismo como meio de desenvolvimento da atividade econômica e da redução do desemprego. Essa conduta, além de prejudicar o mercado de trabalho, também gera prejuízo à Administração Pública, que será tolhida do seu direito e dever de selecionar a proposta mais vantajosa, haja vista que não terá acesso, de fato, a todas as propostas cabíveis.

Palavras-chave: cooperativas de trabalho - licitação - direito administrativo - direito cooperativo - direito do trabalho.

Abstract: The present work aims to analyze the statement of Súmula num. 281 of the Federal Audit Court, approved in July 11, 2012, which prohibits the participation of labor cooperatives in bids when the service to be provided requires the need for subordination, habituality and personality. Although the provisions of the Bidding Law and the Law of Labor Cooperatives provide that said impediment is prohibited, many bidding procedures, due to the summary, exclude this type of society from participation, which causes principles such as legality and equality to be violated, as well as affronts the constitutional precept of fostering cooperativism as a means of developing economic activity and reducing unemployment. This conduct, in addition to harming the labor market, also causes damage to the public administration, which will be restricted from its right and duty to select the most advantageous proposal, since it will not have access, in fact, to all the appropriate proposals.

Keywords: labor cooperatives - bidding - administrative law - cooperative law - labor law. 


\section{Introdução}

O cooperativismo é um movimento que tem como fim social o auxílio às pessoas, permitindo-as a alcançar objetivos conforme o objeto social da sociedade. A partir da associação, o cooperado passa a ter acesso aos serviços prestados pela cooperativa de maneira a ter desenvolvimento socioeconômico, devendo, para tanto, observar, também, as obrigações associativas.

A relação dos associados com a cooperativa apresenta caráter de dupla qualidade, já que além de utilizarem os serviços prestados, também são donos do negócio e devem exercer suas funções como tal, gerindo a atividade e tomando as decisões necessárias para a manutenção e continuidade da sociedade.

Dentre os muitos ramos existentes, encontram-se as cooperativas de trabalho, produção de bens e serviços, que surgiu da necessidade de garantir o trabalho a quem se associar, frente ao desemprego e às más condições de trabalho. Dessa forma, profissionais com o mesmo interesse laboral se unem para gerir um negócio, a fim de que a sociedade realize a intermediação da prestação dos serviços, tornando-se membro da sociedade.

Essa relação não gera vínculo de emprego com a cooperativa, tampouco com o tomador dos serviços, uma vez que a relação com a primeira é associativa e a contratação do serviço por um terceiro objetiva a realização de uma obra ou tarefa a ser concretizada pelos associados de forma autônoma e sem a obrigatoriedade de que o prestador seja sempre a mesma pessoa, o que afasta a característica da pessoalidade. Ao fim e ao cabo, o tomador de serviços busca a concretização de uma obra ou tarefa, enquanto a cooperativa tem o interesse no pagamento do valor contratado.

Por essa razão, a principal característica formadora da relação de emprego encontra-se ausente, qual seja, a subordinação (subalternidade hierárquica que obriga o subordinado a cumprir ordens e instruções de pessoa com cargo superior), uma vez que o cooperado exerce seu serviço de forma autônoma e, por serem donos do negócio a que pertencem regem-se pelo princípio da singularidade do voto e da regra da soberania assemblear, ademais de terem direito ao retorno das sobras líquidas do exercício e obrigação ao rateio das despesas e de prejuízos durante o exercício, bem como subscrevem quotas-partes para integrarem a cooperativa.

A contratação dessas cooperativas fomenta o desenvolvimento da independência laboral e socioeconômico, além de ser um grande aliado no combate ao desemprego. Contudo, no início dos anos 2000, foram 
impostas muitas restrições às cooperativas de trabalho, de forma a proteger as relações laborais e a evitar a utilização da terceirização irregular, em razão de o Ministério Público do Trabalho (MPT) ter combatido as falsas cooperativas.

Com isso, foi aprovado, pelo Tribunal de Contas da União (TCU), o enunciado de Súmula n. 281, a fim de sedimentar as decisões do órgão proibindo a participação das cooperativas de trabalho nos procedimentos licitatórios, embora leis contemporâneas à súmula do TCU impeçam qualquer discriminação com relação a essas sociedades no âmbito licitatório.

Tanto as leis como a doutrina entendem que, se a cooperativa de trabalho for constituída de forma a observar as normas cooperativistas e a exercer sua atividade como tal, assim como o trabalho prestado pelos cooperados ocorrer, de fato, de forma autônoma, sem qualquer interferência do tomador de serviço além daquilo previsto no contrato de terceirização, inexiste qualquer ilícito na prestação do serviço terceirizado.

Desse modo, faz-se necessário observar os equívocos incorridos pelo enunciado de Súmula n. 281 do TCU, a fim de apontar os pontos onde a decisão encontra-se em dissonância com a legislação, a doutrina e os princípios que regem tanto o cooperativismo como a administração pública, a fim de que seja possível sua adequação urgente às normas correntes.

\section{O cooperativismo de trabalho}

De acordo com os professores Amílcar Barca Teixeira Júnior e Lívio Ciotti, o cooperativismo é o meio mais eficiente para o estabelecimento da relação capital-trabalho, ao promover a independência laboral do ser humano, ademais de ser um meio eficaz na promoção e no desenvolvimento socioeconômico².

Sendo assim, as cooperativas de trabalho objetivam gerar trabalho produtivo, treinamento e proteção ao trabalhador, sem qualquer caráter paternalista ou assistencialista, melhorando a renda de seus associados ao intermediar a prestação de serviços de seus cooperados, expressos em forma de tarefa, obra ou serviço, com os seus contratantes, pessoas físicas ou jurídicas, não produzindo bens ou serviços pró-

2 TEIXEIRA JUNIOR, Amílcar Barca; CIOTTI, Lívio Rodrigues. Cooperativas de trabalho na Administração Pública. Belo Horizonte: Mandamentos, 2003, p. 73. 
prios $^{3-4}$. Desse modo, tem-se por associado/cooperado o trabalhador da mesma profissão ou não, porém, de uma mesma classe, ou seja, trabalhadores com identidade de interesses em razão de sua atividade laborativa, que se torna dono do capital do empreendimento cooperativo e autogestor dos negócios comuns 5 .

Cumpre destacar que os cooperados não são empregados da cooperativa, nem, tampouco, prestam serviços a ela. Por sua vez, são as cooperativas que prestam serviços a seus cooperados, pois agenciam a prestação de serviços entre tomador e prestador de serviço. Por serem prestadoras de serviço, valem-se de todas as regras de terceirização aplicadas às empresas prestadoras de serviços desse gênero, embora doutrinadores afirmem que não caberia o enquadramento nas hipóteses de terceirização, por inexistir a figura da empresa interposta, cabendo denominar a hipótese como secundarização ${ }^{6}$.

Originaram-se no movimento cooperativista francês, tendo como base um artigo publicado em 1881, de autoria de Philippe Bouchez, que traça as linhas gerais da operacionalização das cooperativas de trabalho até os dias atuais ${ }^{7}$, e os princípios rochdaleanos, tendo surgido

3 PINHO, Diva Benevides. <Cooperativas de trabalho e emprego produtivo>. In: PINHO, Diva Benevides (organ.). Tipologia cooperativista. 3. ${ }^{a}$ ed.. vol. 4. São Paulo: CNPq, 1984, p. 252.

4 ALMEIDA, Rachel Pereira de e KACZUROWSKI, Sofia. <Cooperativismo na Previdência Social>. In: KRUEGER, Guilherme (Coord.). Comentários à Legislação das Sociedades Cooperativas - Tomo II. Belo Horizonte: Mandamentos, 2007, p. 187.

5 POLONIO, Wilson Alves. Manual das Sociedades Cooperativas. 3. ${ }^{a}$ ed. São Paulo: Atlas, 2001, p. 54.

6 CARDONE, Vanessa. Cooperativas de trabalho: legalidade e subsistência. São Paulo: Antigua, 2007, p. 31 e 32.

7 As cooperativas de trabalho tiveram origem na França, tendo por fonte de inspiração um artigo de PHILIPPE BOUCHEZ, publicado no Journal des Sciences Morales et Politiques em 17/12/1881 (CUESTA, 1987:200-203). Naquela oportunidade, BOUCHEZ formulou um sistema de trabalho por associação, cujas linhas gerais continuam observadas até hoje nas operações realizadas pelas cooperativas de trabalho:

- Os associados assumem a condição de empreendedores, elegendo entre eles um ou mais representantes da sociedade;

- Cada um deles continuaria recebendo uma remuneração segundo os padrões correntes para cada profissão, ou seja, por jornada ou tarefa e segundo a habilidade individual;

— O valor equivalente à mais-valia se reverteria em benefício líquido, se repartindo da seguinte forma: parte para reservas e investimentos no empreendimento, em assistência para os associados e para distribuição entre os associados, pro rata de seu trabalho;

- Recursos para reserva e investimentos pertencem à sociedade e são indivisíveis entre os associados, a fim de se prevenir que ela se reduza a um mero meio de exploração, igual a qualquer empresa; 
como reação à Revolução Industrial e como uma alternativa ao desemprego, haja vista a participação democrática e a equidade na distribuição dos rendimentos deste ramo societário.

Diante da precarização das relações laborais, da falta de oportunidades e postos de trabalho, seja para a mão de obra semiqualificada, seja para profissionais técnicos especializados, as cooperativas de trabalho se mostram como uma opção viável para ingresso no mercado de trabalho brasileiro, sendo um dos sete ramos de cooperativas existentes no país, conforme dados da Organização das Cooperativas Brasileiras $(\mathrm{OCB})^{8}$.

No Brasil, as cooperativas de trabalho tiveram sua conceituação definida pela primeira vez pelo artigo 24 do Decreto-lei n. 22.232/329.

Art. 24. São cooperativas de trabalho aquelas que, constituídas entre operários de uma determinada profissão ou de ofício ou de ofícios vários de uma mesma classe, têm como finalidade primordial melhorar os salários e as condições de trabalho pessoal de seus associados e, dispensando a intervenção de um patrão ou empresário, se propõem contratar obras, tarefas, trabalhos ou serviços públicos ou particulares, coletivamente por todos ou por grupos de alguns.

A Lei n. 5.764/71 e, posteriormente, a Lei n. 8.949/94 afirmam a inexistência de vínculo empregatício entre as cooperativas e seus associados, tendo esta última estatuído a inexistência de vínculo entre os tomadores de serviço e as cooperativas, conforme expresso no parágrafo único do artigo 442 da CLT. Contudo, se observada a subordinação, a não eventualidade e a pessoalidade, caracterizar-se-á o vínculo empregatício.

Atualmente, as cooperativas de trabalho brasileiras são regidas pela Lei $n$. 12.690/2012, que as define, em seu artigo $2 .^{\circ}$, como «a socie-

- A sociedade não poderia fazer trabalhar permanentemente em seu benefício trabalhadores estranhos, sendo obrigada a admitir o número necessário de trabalhadores novos que se fizessem necessários pelo aumento das operações realizadas pela sociedade.

KRUEGER, Guilherme. Cooperativas de trabalho na terceirização. 2. ${ }^{a}$ ed. rev. e ampl. com comentários à Lei 12.690/2012. Belo Horizonte: Del Rey, 2014, p. 45-46.

8 De acordo com a OCB, a divisão das cooperativas em ramos foi realizada com o intuito de facilitar a sua organização e representação, reunindo as cooperativas pelo tipo de trabalho que fazem.

BRASIL. OCB. Ramos do Cooperativismo. Disponível em: https://www.ocb.org.br/ ramos. Acesso em 07.out.2020.

9 BRASIL. Decreto-lei n. 22.239, de 19 de dezembro de 1932. Disponível em http:// www.planalto.gov.br. Acesso em 07.out.2020. 
dade constituída por trabalhadores para o exercício de suas atividades laborativas ou profissionais com proveito comum, autonomia e autogestão para obterem melhor qualificação, renda, situação socioeconômica e condições gerais de trabalho ${ }^{10} »$.

De acordo com o artigo $3 .^{\circ}$ da citada lei, serão regidas pelos seguintes princípios e valores: adesão voluntária e livre; gestão democrática; participação econômica dos membros; autonomia e independência; educação, formação e informação; intercooperação; interesse pela comunidade; preservação dos direitos sociais, do valor social do trabalho e da livre iniciativa; não precarização do trabalho; respeito às decisões de assembleia, observado o disposto nesta Lei; participação na gestão em todos os níveis de decisão de acordo com o previsto em lei e no Estatuto Social.

Referido artigo consolida, na norma vigente, os princípios cooperativos elencados pela Aliança Cooperativa Internacional, tornando obrigatória sua aplicação.

\section{A relação de trabalho}

Segundo Délio Maranhão, a prestação de trabalho se divide em dois ramos de atividade, o trabalho subordinado e o trabalho autônomo, cuja origem advém do locatio operis (ocorre quando o resultado do trabalho importa e o risco permanece a cargo do realizador da obra) e locatio operarum (o que importa é a força do trabalho e o risco recai sobre aquele que adquire o direito de dispor do trabalho alheio) do Direito Romano ${ }^{11}$.

Tendo em vista essa distinção, mencionado autor afirma ser admissível a distinção terminológica quanto à relação jurídica de trabalho, que resulta de um contrato de trabalho, tratando-se de relação de emprego quando há um contrato de trabalho subordinado e relação de trabalho quando inexista contrato ${ }^{12}$.

Esse contraste, no Brasil, é oriundo de construção jurisprudencial, que define relação de emprego como aquela relação que compreende

10 BRASIL. Lei n. 12.690, de 19 de julho de 2012. Disponível em http://www. planalto.gov.br. Acesso em 07.out.2020.

11 SÜSSEKIND, Aranaldo et al.. Instituições de Direito do Trabalho. Vol. 1. 22. ${ }^{\text {a ed. }}$ atual. por Arnaldo Süssekind e João Lima Teixeira Filho. São Paulo: LTr, 2005, p. 232.

12 SÜSSEKIND, Aranaldo et al.. Instituições de Direito do Trabalho. Vol. 1. 22. ${ }^{a}$ ed. atual. por Arnaldo Süssekind e João Lima Teixeira Filho. São Paulo: LTr, 2005, p. 233. 
o trabalho subordinado, enquanto a relação de trabalho inclui, também, o trabalho autônomo ${ }^{13}$.

\subsection{Contrato de trabalho}

Nos termos do artigo 442 da CLT, o «contrato individual de trabalho é o acordo tácito ou expresso, correspondente à relação de emprego» e, de acordo com o seu artigo $3 .^{\circ}$, será considerado empregado «toda pessoa física que presta serviço de natureza não eventual a empregador, sob a dependência deste e mediante salário» ${ }^{14}$.

O professor Luiz de Pinho Pedreira da Silva, ao citar Mozart Victor Russomano, afirma que a relação de emprego pressupõe a subordinação hierárquica, elemento que caracteriza o contrato de trabalho ${ }^{15}$.

Para Orlando Gomes, o contrato de trabalho é «a convenção pela qual um ou vários empregados, mediante certa remuneração e em caráter não eventual, prestam trabalho pessoal em proveito e sob a direção de empregador ${ }^{16}$ », enquanto para Délio Maranhão o «contrato de trabalho stricto sensu é o negócio jurídico pelo qual uma pessoa física (empregado) se obriga, mediante o pagamento de uma contraprestação (salário), a prestar trabalho não eventual em proveito de outra pessoa, física ou jurídica (empregador), a quem fica juridicamente subordinada ${ }^{17}$ 》.

Tem-se, assim, que o contrato de trabalho possui como requisitos a subordinação, a pessoalidade, a onerosidade e a continuidade, podendo ser acordado de forma tácita ou expressa, verbalmente ou por escrito.

Tendo em vista que a subordinação é o elemento fundamental para a caracterização desse tipo contratual, esclarece-se que ela nada mais é que o direito geral de fiscalização da atividade de outrem, bem como o direito de interromper ou suscitar essa atividade ou, ainda, de limitá-la sem a necessidade de controlar continuamente o valor do trabalho efe-

13 SILVA, Luiz de Pinho Pedreira da. <As concepções da relação de trabalho>. In: Revista de Direito do Trabalho, vol. 127, jul-set/2007, p. 132-145.

14 BRASIL. Consolidação das Leis do Trabalho, Lei n. 5.452, de 1. de maio de 1943. Disponível em http://www.planalto.gov.br. Acesso em 11.out.2020.

15 SILVA, Luiz de Pinho Pedreira da. <As concepções da relação de trabalho>. In: Revista de Direito do Trabalho, vol. 127, jul-set/2007, p. 132-145.

16 GOMES, Orlando; GOTTSCHALK, Elson. Curso de Direito do Trabalho. Rio de janeiro: Forense, 1990, p. 130.

17 SÜSSEKIND, Aranaldo et al.. Instituições de Direito do Trabalho. Vol. 1. 22. a ed. atual. por Arnaldo Süssekind e João Lima Teixeira Filho. São Paulo: LTr, 2005, p. 241. 
tuado. Desse modo, os seus dois pilares centram-se na direção e fiscalização ${ }^{18}$.

Como nas cooperativas de trabalho os associados são donos do negócio, referido tipo contratual a eles não é aplicado.

\subsection{O ato cooperativo nas cooperativas de trabalho}

O cooperado, ao relacionar-se com a cooperativa da qual participa, o faz por intermédio do que é denominado contrato de sociedade cooperativa, nos moldes do artigo $3 .^{\circ}$ da Lei $.^{\circ} 5.764 / 71^{19}$, que gera o denominado ato cooperativo:

Art. 79. Denominam-se atos cooperativos os praticados entre as cooperativas e seus associados, entre estes e aquelas e pelas cooperativas entre si quando associados, para a consecução dos objetivos sociais.

Parágrafo único. O ato cooperativo não implica operação de mercado, nem contrato de compra e venda de produto ou mercadoria 20 .

Tem-se que o ato cooperativo é a expressão jurídica da solidariedade, do esforço próprio e da ajuda mútua, diferenciando-se do negócio jurídico ordinário, uma vez que este prima pelo enfrentamento das partes. Ademais, os cooperados dirigem o ato cooperativo para si e, por isso, não há agressão à esfera jurídica alheia; nem há possibilidade de uma vontade avassalar outra inerente ao negócio; não existe, também, um terceiro estranho ao ato, submetido a uma declaração de vontade na qual não teve participação; não existe fonte de arbitrariedade, sendo, portanto, um ato que conjuga os interesses gerais e individuais dos associados, além de não prever cláusulas leoninas em razão da essencial igualdade existente entre os membros ${ }^{21}$.

18 GOMES, Orlando; GOTTSCHALK, Elson. Curso de Direito do Trabalho. Rio de janeiro: Forense, 1990, p. 144.

19 Art. $3^{\circ}$ Celebram contrato de sociedade cooperativa as pessoas que reciprocamente se obrigam a contribuir com bens ou serviços para o exercício de uma atividade econômica, de proveito comum, sem objetivo de lucro.

BRASIL. Lei n. 5.764, de 16 de dezembro de 1971. Disponível em http://www. planalto.gov.br. Acesso em 11.out.2020.

20 BRASIL. Lei n. 5.764, de 16 de dezembro de 1971. Disponível em http://www. planalto.gov.br. Acesso em 11.out.2020.

21 PASTORINO, Roberto Jorge. Teoría General del Acto Cooperativo. Buenos Aires: INTERCOOP Editora Cooperativa, 1993, p. 34 e 42. 
$\mathrm{Na}$ cooperativa de trabalho, o ato cooperativo é o negócio-fim da cooperativa e é celebrado unicamente com os associados, sem a finalidade de gerar qualquer tipo de resultado financeiro, ou seja, a cooperativa tem como objeto a prestação de serviços que é realizada pelos seus membros, organiza suas atividades, prepara os planos a serem desenvolvidos pelos sócios, oferece e firma, em nome dos sócios, os contratos com os interessados na prestação do serviço e, ao receber em nome dos membros, repassa a eles a totalidade dos resultados da produção contratada22.

Da mesma forma que essa relação entre cooperativa e cooperado não se enquadra na relação de emprego, tampouco enquadrar-se-á a relação entre o associado e o tomador de serviços.

Cabe destacar que a prestação de serviços pelos sócios ocorre em relação a terceiros e não gera qualquer vínculo de emprego entre as partes, afastando, por isso, a característica da pessoalidade. Isso sucede pelo fato de a contratação da cooperativa laboral pelo tomador de serviço objetivar a realização de uma obra ou tarefa, que será realizada pelos associados da cooperativa sem que haja a obrigatoriedade de que seja sempre o mesmo trabalhador e sem interveniência do tomador, uma vez que o interesse do tomador de serviço é a realização da obra ou tarefa, enquanto da cooperativa é o pagamento do valor contratado 23 .

Na prática, essa prestação de serviços deve demonstrar a existência de autonomia ou a eventualidade do cooperado em relação ao tomador, que, ao realizar o mero acompanhamento, demonstrará apenas a exigência de que o contrato seja cumprido, como qualquer contratante faria, caracterizando a inexistência de vínculo ${ }^{24}$.

22 TEIXEIRA JÚNIOR, Amílcar Barca e CIOTTI, Lívio Rodrigues. Participação de Cooperativas em Procedimentos Licitatórios. Belo Horizonte: Mandamentos, 2002, p. 161.

23 SILVA FILHO, Cícero Virgulino da. Cooperativas de Trabalho. São Paulo: Atlas, 2001, p. 84.

24 Em síntese, o que se deve buscar numa investigação sobre a legalidade de um serviço terceirizado contratado junto à Cooperativa de Trabalho é a observância de três condições na relação de trabalho:

1. A autonomia ou a eventualidade da atividade laborativa do cooperado em relação a preposto da empresa tomadora dos serviços da Cooperativa. Em outras palavras, o que a Cooperativa contratou foi um resultado, e não simplesmente uma alocação de força de trabalho para ficar à disposição do tomador.

2. A equidade na distribuição de riscos e benefícios, investimento e retorno entre Cooperados. Isto é, a inexistência de enriquecimento de diretor, cooperado ou terceiro, desproporcional à contribuição nos esforços solidários entre cooperados - o que pode evidenciar a intermediação ilegal de mão-de-obra. 
Tem-se, então, o que se chama de relação de trabalho, que, nas palavras de Arion Sayão Romita é a relação jurídica instaurada sempre que um trabalhador se obriga à prestação de trabalho em proveito de outrem, abrangendo as formas de trabalho desinteressado (gratuito, isto é, não-oneroso), assim como de trabalho prestado em regime de autonomia, mediante remuneração ${ }^{25}$.

\subsection{A terceirização do trabalho}

A terceirização é um fenômeno mundial que surgiu a partir do momento em que se verifica o desemprego em uma sociedade. Deriva da palavra latina tertius, que significa o estranho a uma relação entre duas pessoas, e foi trazido ao Brasil, na década de 50, por empresas multinacionais ${ }^{26}$.

Pode-se definir a terceirização como «um processo de gestão empresarial consistente na transferência para terceiros (pessoas físicas ou jurídicas) de serviços que originalmente seriam executados dentro da própria empresa ${ }^{27} »$.

O objetivo da terceirização é permitir que as empresas se concentrem em suas atividades primordiais, liberando-a das atividades acessórias, também conhecidas como atividades meios, a fim de que o resultado final seja a produção mais eficiente e qualificada, tendo, como consequência, a redução de custos (operacionais, despesas administrativas, encargos trabalhistas e previdenciários)28.

Para que ela decorra de forma apropriada, não poderá haver conflito com as leis de proteção ao trabalho e aquele que presta serviços ou produz bens para terceiros deverá dispor de equipamentos, maté-

3. O regime de autogestão. Independentemente da forma de execução dos serviços contratados, da origem dos cooperados e das circunstâncias que cercam a celebração do contrato, deve-se observar se todos os cooperados tiveram a oportunidade de participar, direta ou indiretamente, na determinação da forma de prestação dos serviços numa cooperativa regularmente constituída.

KRUEGER, Guilherme. Cooperativas de Trabalho na Terceirização. Belo Horizonte: Mandamentos, 2003, p. 161-162.

25 SILVA, Luiz de Pinho Pedreira da. <As concepções da relação de trabalho>. In: Revista de Direito do Trabalho, vol. 127, jul-set/2007, p. 132-145.

26 MARTINS, Sérgio Pinto. A terceirização e o Direito do Trabalho. 5 ed. rev. e ampl.. São Paulo: Atlas, 2001, p. 15-16 e 19.

27 POLONIO, Wilson Alves. Terceirização: aspectos legais, trabalhistas e tributários. São Paulo: Atlas, 2000, p. 97.

28 POLONIO, Wilson Alves. Terceirização: aspectos legais, trabalhistas e tributários. São Paulo: Atlas, 2000, p. 98. 
ria-prima e empregados próprios, cujo vínculo se dá em face da empresa prestadora ${ }^{29}$.

A cooperativa pode ser uma forma de terceirização lícita e, para tanto, segue as mesmas regras de terceirização aplicadas às sociedades comerciais.

Para Guilherme Krueger, os associados das cooperativas, ao prestarem serviços a terceiros, não assumem a posição de prepostos da cooperativa e inexiste vínculo de emprego diante da ausência dos elementos formadores dessa relação, ainda que haja cumprimento de horários, de procedimentos, de rotinas e de organização de trabalho em equipes. Isso ocorre uma vez que no cooperativismo devem ser observados o princípio da singularidade do voto, a regra da soberania assemblear, o retorno das sobras líquidas do exercício dos associados, o rateio das despesas e de prejuízos durante o exercício, bem como a necessidade de subscrição das quotas-partes, requisitos estes que afastam a subordinação dos cooperados ${ }^{30}$.

\section{A terceirização na Administração Pública}

A terceirização pode ser exercida em diversos âmbitos, podendo ser regulada pelo direito civil, pelo direito comercial, ou ainda, pelo direito administrativo.

No âmbito da Administração Pública, a terceirização iniciou-se com o Decreto-Lei n. 200/67, que previa, em seu artigo 10. ${ }^{\circ}$, a descentralização das atividades da Administração Federal, com o intuito de exercer melhor as tarefas de planejamento, coordenação, supervisão e controle, exigindo, para tanto, a celebração de contrato ${ }^{31}$.

Essa prática é tutelada pelo inciso XXI, do artigo 37 e pelo artigo 175, ambos da Constituição Federal, que disciplinam, respectivamente, que «obras, serviços, compras e alienações serão contratados mediante processo de licitação pública que assegure igualdade de condições a todos os concorrentes, com cláusulas que estabeleçam obrigações de pagamento, mantidas as condições efetivas da proposta, nos termos da lei» e que «incumbe ao Poder Público, na forma da lei, dire-

29 TEIXEIRA JÚNIOR, Amílcar Barca; CIOTTI, Lívio Rodrigues. Cooperativas de Trabalho na Administração Pública. Belo Horizonte: Mandamentos, 2003, p. 45.

30 KRUEGER, Guilherme. Cooperativas de trabalho na terceirização. 2 ed. rev. e ampl. com comentários à Lei 12.690/2012. Belo Horizonte: Del Rey, 2014, p.170-171.

31 BRASIL. Decreto-Lei n.200, de 25 de fevereiro de 1967. Disponível em http:// www.planalto.gov.br. Acesso em 13.out.2020. 
tamente ou sob regime de concessão ou permissão, sempre através de licitação, a prestação de serviços públicos» 32 .

Atualmente, o Decreto n. 9.507/2018 elenca as atividades que não podem ser exercidas de forma indireta pela Administração ${ }^{33}$.

Cumpre destacar que a descentralização pressupõe a existência de pessoa distinta do Estado no exercício da atividade administrativa, que agirá em nome próprio, por outorga do serviço ou atividade, ou por delegação ${ }^{34}$.

O exercício dessa atividade se dará mediante a celebração de um contrato. De acordo com o mestre Hely Lopes Meirelles, «contrato de serviço é todo ajuste administrativo que tem por objeto uma atividade prestada à Administração, para atendimento de suas necessidades ou de seus administrados» e sua diferença com obra decorre da predominância da atividade sobre o material utilizado. Ele ainda distingue os serviços como comuns, técnicos profissionais e artísticos ${ }^{35}$.

Os serviços comuns não exigem habilitação especial e podem ser realizados por qualquer pessoa ou empresa, assim como só podem ser contratados mediante licitação prévia, a fim de que a Administração obtenha o melhor serviço pelo melhor preço.

32 BRASIL. Constituição de República Federativa do Brasil de 1988. Disponível em http://www.planalto.gov.br. Acesso em 13.out.2020.

33 Art. 3. ${ }^{\circ}$ Não serão objeto de execução indireta na administração pública federal direta, autárquica e fundacional, os serviços:

I. que envolvam a tomada de decisão ou posicionamento institucional nas áreas de planejamento, coordenação, supervisão e controle;

II. que sejam considerados estratégicos para o órgão ou a entidade, cuja terceirização possa colocar em risco o controle de processos e de conhecimentos e tecnologias;

III. que estejam relacionados ao poder de polícia, de regulação, de outorga de serviços públicos e de aplicação de sanção; e

IV. que sejam inerentes às categorias funcionais abrangidas pelo plano de cargos do órgão ou da entidade, exceto disposição legal em contrário ou quando se tratar de cargo extinto, total ou parcialmente, no âmbito do quadro geral de pessoal.

$\S 1 .^{\circ}$ Os serviços auxiliares, instrumentais ou acessórios de que tratam os incisos do caput poderão ser executados de forma indireta, vedada a transferência de responsabilidade para a realização de atos administrativos ou a tomada de decisão para o contratado.

BRASIL. Decreto n. 9.507, de 21 de setembro de 2018. Disponível em http://www. planalto.gov.br. Acesso em 13.out.2020.

34 MEIRELLES, Hely Lopes. Direito Administrativo Brasileiro. 16. Ed. atual. pela Constituição de 1988, 2. tiragem. São Paulo: Editora Revista dos Tribunais, 1991, p. 632.

35 MEIRELLES, Hely Lopes. Direito Administrativo Brasileiro. 16. Ed. atual. pela Constituição de 1988, 2. tiragem. São Paulo: Editora Revista dos Tribunais, 1991, p. 230-231. 
Por sua vez, os serviços técnicos profissionais exigem habilitação legal para a execução, como, por exemplo, registro profissional ou diploma. Podem se subdividir em generalizados (aqueles que não demandam maiores conhecimentos teóricos ou práticos e sua contratação, em regra, exige licitação prévia) e especializados (exige que o prestador de serviços possua conhecimentos reconhecidos, podendo ser dispensada a licitação quando a especialização for notória).

Por fim, os serviços artísticos buscam a realização de uma obra de arte, tratando-se de serviço profissional e técnico e, como os demais, exige a realização de licitação.

Dessa forma, verifica-se que a terceirização demanda, na maioria dos casos, a participação em licitação prévia e, para tanto, é necessário seguir regras específicas disciplinadas pela Lei de Licitações e Contratos da Administração Pública (Lei n. 8.666/93).

\subsection{A licitação de serviços públicos}

A licitação é o requisito prévio à celebração do contrato com a administração, sendo conceituada como o meio pelo qual a Administração Pública abre uma disputa para os interessados em estabelecer uma relação negocial com o Poder Público, que escolherá a proposta mais vantajosa e que observe os princípios da eficiência e moralidade administrativa no cumprimento das obrigações a serem assumidas.

O procedimento licitatório está previsto na Constituição Federal -artigo 37, XXI e artigo 175- e a lei geral que rege o procedimento licitatório é a Lei n. 8.666/93 e deve observar alguns princípios ${ }^{36}$.

O professor Celso Antônio Bandeira de Mello esclarece que:

a) o princípio da legalidade está descrito no artigo $4 .{ }^{\circ}$ da Lei de Licitações e obriga a observância à lei;

b) o princípio da impessoalidade determina o tratamento neutro entre os participantes, de forma a evitar favoritismos e/ou discriminações;

36 Art. $3^{\circ} \mathrm{A}$ licitação destina-se a garantir a observância do princípio constitucional da isonomia, a seleção da proposta mais vantajosa para a administração e a promoção do desenvolvimento nacional sustentável e será processada e julgada em estrita conformidade com os princípios básicos da legalidade, da impessoalidade, da moralidade, da igualdade, da publicidade, da probidade administrativa, da vinculação ao instrumento convocatório, do julgamento objetivo e dos que lhes são correlatos.

BRASIL. Lei n. 8.666, de 21 de junho de 1993. Disponível em http://www.planalto. gov.br. Acesso em 13.out.2020. 
c) o princípio da igualdade vai além do tratamento isonômico, já que ele também oportuniza a participação de qualquer pessoa que se interesse pelo certame;

d) o princípio da publicidade obriga que todos os atos e termos do procedimento estejam disponíveis para conhecimento de qualquer interessado;

e) o princípio da moralidade rege os padrões éticos que se espera no desenvolvimento do procedimento;

f) o princípio da vinculação ao instrumento convocatório disciplina a necessidade de seguir estritamente as regras estabelecidas na licitação; e

g) o princípio do julgamento objetivo pretende o afastamento de qualquer caráter de subjetividade ${ }^{37}$.

A licitação poderá ter como objetos obra, serviço, compra, alienação ou concessão a ser contratada pelo particular e tem como pressuposto a pluralidade de ofertas. Diante disso, qualquer pessoa que preencha os requisitos previstos no edital da licitação poderá participar, inclusive cooperativas.

\subsection{Participação de cooperativas em licitações}

As cooperativas de trabalho não podem ser excluídas dos procedimentos licitatórios que tenham por escopo as mesmas operações, atividades e serviços previstos em seu estatuto social, conforme inteligência do $\S 2 .{ }^{\circ}$, do artigo 10, da Lei n. 12.690/2012. Corroborando esse entendimento, o $\$ 1 .{ }^{\circ}$, do artigo $3 .^{\circ}$, da Lei $8.666 / 93$, dispõe que é vedada a inclusão de cláusulas ou condições que restrinjam as cooperativas.

O Tribunal de Contas da União, em seu livro de 2010, explicitou ser lícita a contratação de cooperativas, desde que se cumpram dois requisitos: os serviços licitados devem ser prestados em caráter coletivo e deve haver completa autonomia dos cooperados, tanto com relação à cooperativa, como com relação ao tomador de serviço ${ }^{38}$.

Qualquer distinção que seja feita no procedimento licitatório com relação aos participantes viola o princípio da igualdade, norteador da

37 MELLO, Celso Antônio Bandeira de. Curso de Direito Administrativo. 27 ed. rev. e atual. até a Emenda Constitucional 64, de 4.2.2010. São Paulo: Editora Malheiros, 2010, p. 532-536.

38 BRASIL. TCU. Licitações e contratos: orientações e jurisprudência do TCU. 4 ed. rev., atual. e ampl.. Brasília: TCU, Secretaria da Presidência: Senado Federal, secretaria Especial de Editoração e Publicações, 2010, p. 317. 
licitação, ademais de prejudicar a competição necessária ao ato, uma vez que impede que a Administração Pública tenha acesso, de fato, à proposta mais vantajosa ao excluir interessados.

Ocorre, no entanto, que em 11 de julho de 2012 foi aprovado o enunciado de Súmula n. 281 do TCU, que impede as cooperativas de participarem de procedimentos licitatórios ${ }^{39}$.

\subsection{Súmula n. 281 do TCU}

O Tribunal de Contas da União é órgão de controle externo do governo federal, previsto na Constituição, independente e autônomo, que auxilia o Congresso Nacional nesse controle, sendo o responsável pela fiscalização contábil, financeira, orçamentária, operacional e patrimonial dos órgãos e entidades públicas do país.

Segundo o artigo 85 do Regimento Interno do órgão, «a Súmula da Jurisprudência constituir-se-á de princípios ou enunciados, resumindo teses, soluções, precedentes e entendimentos, adotados reiteradamente pelo Tribunal, ao deliberar sobre assuntos ou matérias de sua jurisdição e competência ${ }^{40}$ ». Assim, nasceu o enunciado de Súmula n. 281 do TCU, com base em julgados do órgão entre 2003 e 2006.

Cumpre destacar que, no período dos julgados que fundamentaram a súmula, as cooperativas de trabalho foram amplamente acusadas pelo Ministério Público do Trabalho de fraudar as normas trabalhistas, por acreditar que a contratação desse ramo cooperativista seria uma forma das empresas se esquivarem do pagamento das obrigações trabalhistas e previdenciárias ${ }^{41}{ }_{4} 42$. Isso se deveu ao surgimento de falsas cooperativas, que se revestiam da estrutura do cooperativismo para

\section{SÚMULA N. ${ }^{\circ} 281$}

É vedada a participação de cooperativas em licitação quando, pela natureza do serviço ou pelo modo como é usualmente executado no mercado em geral, houver necessidade de subordinação jurídica entre o obreiro e o contratado, bem como de pessoalidade e habitualidade.

BRASIL. TCU. Súmula $n .^{\circ}$ 281. Disponível em http://www.portal.tcu.gov.br. Acesso em 14.out.2020.

40 BRASIL. TCU. Regimento Interno. Disponível em Disponível em http://www. portal.tcu.gov.br. Acesso em 14.out.2020.

41 TEIXEIRA JÚNIOR, Amílcar Barca e CIOTTI, Lívio Rodrigues. Cooperativas de Trabalho na Administração Pública. Belo Horizonte: Mandamentos, 2003, p. 353 a 357.

42 TEIXEIRA JÚNIOR, Amílcar Barca e CIOTTI, Lívio Rodrigues. Cooperativas de Trabalho e o Termo de Conciliação Judicial AGU-MPT. Belo Horizonte: Mandamentos, 2005, p. 49 a 58. 
exercer a atividade como uma empresa comum, sem a obrigação de cumprir com as normas trabalhistas inerentes ao empregado.

Acontece que inexiste qualquer tipo de irregularidade se a cooperativa de trabalho atuar conforme a legislação que rege o cooperativismo, de acordo com os valores e princípios atribuídos ao movimento. Além disso, a fim de sedimentar essa regularidade, foi promulgada a lei n. 12.690/2012, regulamentando a atividade exercida pelas cooperativas de trabalho.

Sendo assim, a manutenção do enunciado de súmula n. 281 do TCU é um erro, em razão de seu teor estar em dissonância com a norma vigente.

O primeiro motivo é relativo à questão do ordenamento jurídico brasileiro seguir a tradição romano-germânica, tendo a Lei de Introdução às Normas do Direito Brasileiro (LINDB) estabelecido a lei como fonte principal no direito nacional, de modo a aplicar a analogia, os costumes e os princípios gerais do direito apenas quando a lei inexistir ou for omissa.

Desta feita, se existe lei que disciplina a impossibilidade de exclusão das cooperativas dos procedimentos licitatórios, o enunciado de Súmula n. 281 do TCU encontra-se em clara dissonância com a norma, ferindo, por isso, o princípio da legalidade.

O segundo motivo advém do fato de que as súmulas passaram a ter um caráter vinculante, de aplicação obrigatória para os tribunais, devido a nova redação do Código de Processo Civil (CPC) ${ }^{43}$. Sem embargo, essa vinculação se apresenta apenas para os órgãos do Poder Judiciário.

Assim, tendo em vista o TCU não estar vinculado a nenhum poder e, por conseguinte, não fazer parte da estrutura do Poder Judiciário, a vinculação das súmulas, prevista nos artigos 926 e 927 do CPC, não se aplica a ele. Por essa razão, não existe possibilidade de discussão quanto à prevalência do enunciado de súmula sobre a lei.

Por fim, se a natureza do serviço a ser licitada tiver necessidade de subordinação jurídica entre o obreiro e o contratado, bem como de pessoalidade e habitualidade, estar-se-á diante de uma terceirização ilícita, uma vez que esses três requisitos acarretam uma mera simulação de prestação de serviços e a burla ao concurso público ao contratar pessoal.

43 TEIXEIRA, Marianna Ferraz; TEIXEIRA, Marília Ferraz. (2019). «El enunciado de Súmula 602 del Tribunal Superior de Justicia de Brasil, del 22 de febrero de 2018 y la afrenta al acto cooperativo». In: Cooperativismo \& Desarrollo, 27(114), 1-18. Disponível em https://doi.org/10.16925/2382-4220.2019.01.01. Acesso em 14.out.2020. 
O Procurador da Fazenda Nacional, Andre Afeche Pimenta, ao citar Maria Sylvia Zanella di Pietro, afirma que essa contratação busca aparentar legalidade, contudo, há, de fato, o fornecimento de mão-deobra para o Estado 44.

Dessa forma, sabido que a contratação de serviços por intermédio de cooperativa de trabalho deve se dar dentro do escopo de seu estatuto para ser prestado por seus associados de forma autônoma, sem qualquer vínculo de emprego, tem-se que o de Súmula n. 281 do TCU merece ser revista com urgência, sob pena de violar o preceito constitucional de fomento ao cooperativismo, previsto no artigo $174, \S 2 .^{\circ}$, da Constituição Federal.

\section{Conclusão}

A Constituição da República Federativa do Brasil prevê o apoio e o estímulo ao cooperativismo, como forma de promover a atividade econômica no país.

As cooperativas de trabalho, produção de bens e serviços são uma forma de combate ao desemprego e ao subemprego, ao reunir profissionais em um empreendimento próprio para prestar serviços como autônomos por intermédio da cooperativa. Dessa forma, ademais de prover trabalho aos seus associados, permite que eles se desenvolvam socioeconomicamente em condições mais vantajosas.

Esse ramo do cooperativismo é regido pela Lei n. 12.690/2012, que define a cooperativa de trabalho como a sociedade constituída por trabalhadores para o exercício de suas atividades laborativas ou profissionais com proveito comum, autonomia e autogestão para obterem melhor qualificação, renda, situação socioeconômica e condições gerais de trabalho.

Citada lei normatiza os valores e os princípios definidos pela Aliança Cooperativa Internacional, tornando obrigatória sua aplicação no âmbito nacional, além de prever valores e princípios que assegurem essa relação laboral. São eles a adesão voluntária e livre; a gestão democrática; a participação econômica dos membros; a autonomia e a independência; a educação, formação e informação; a intercooperação; o interesse pela comunidade; a preservação dos direitos sociais, do valor social do trabalho e da livre iniciativa; a não precarização do tra-

44 PIMENTA, Andre Afeche. A terceirização ilícita na Administração Pública. Disponível em https://conteudojuridico.com.br/consulta/Artigos/35489/a-terceirizacao-ilicita-naadministracao-publica. Acesso em: 14.out.2020. 
balho; o respeito às decisões de assembleia e a participação na gestão em todos os níveis de decisão de acordo com o previsto em lei e no Estatuto Social. Supletivamente aplicam-se as regras da lei geral das Cooperativas, a Lei n. 5.764/71, para os casos não previstos na legislação específica.

Verifica-se, portanto, que os serviços ofertados por uma cooperativa de trabalho encontram respaldo legal, cabendo a observância às normas durante toda a execução do serviço e quanto à relação da cooperativa com o cooperado e deste com o tomador de serviço.

A relação travada entre a cooperativa e seu cooperado é associativa e culmina com o ato cooperativo, não importando em relação de emprego. De igual forma, tampouco existe relação de emprego se observada a relação entre o cooperado e o tomador de serviço, já que exerce a atividade de forma autônoma e sem a exigência do caráter personalíssimo. No entanto, se na prática houver a presença de subordinação ao tomador, essa relação poderá ser considerada como de emprego, aplicando-se todas as normas trabalhistas atualmente vigentes.

Cumpre destacar que a presença da subordinação ocorre em situações irregulares e, por essa razão, não deve ser tomada como a situação padrão. Desse modo, tendo em vista a prestação de serviços adequada à lei, tem-se que a terceirização por intermédio da cooperativa de trabalho é uma excelente opção.

A terceirização é uma forma de organização que permite a uma empresa transferir a outra o exercício de atividades-meio, a fim de que todo seu esforço esteja concentrado nas atividades-fim, reduzindo, assim, os custos.

A terceirização pode ser exercida em diversos campos e, na Administração Pública, busca a descentralização das atividades públicas com o objetivo de focar nas tarefas de planejamento, coordenação, supervisão e controle, não sendo permitida quando a atividade envolver tomada de decisão ou posicionamento institucional nas áreas de planejamento, supervisão e controle, quando for considerada estratégica para o órgão ou a entidade e cuja terceirização possa colocar em risco o controle de processos, de conhecimento e de tecnologias, quando estiver relacionada ao poder de polícia, de regulação, de outorga de serviços públicos e de aplicação de sanção e quando seja inerente às categorias funcionais abrangidas pelo plano de cargos do órgão ou da entidade, conforme previsão do Decreto n. 9.507/2018.

Para que essa descentralização ocorra, é necessária a celebração de um contrato com a Administração, que nada mais é do que um acordo de vontades entre a Administração Pública e terceiros, que, por força de lei, das cláusulas pactuadas ou do tipo do objeto sofrem com 
a imposição do interesse público. Entretanto, para que esse contrato se concretize, é necessária a realização de licitação prévia.

A licitação é o meio pelo qual a Administração Pública abre uma disputa para os interessados em estabelecer uma relação negocial com o Poder Público. Tem como escopo a escolha da proposta mais vantajosa, devendo observar princípios delimitados por lei, dentre os quais estão o da legalidade e o da igualdade.

Conforme estabelece a Lei n. 8.666/93 e a Lei n. 12.690/2012, as cooperativas não podem ser excluídas dos procedimentos licitatórios, porém, o enunciado de Súmula n. 281 do TCU dispõe a vedação de participação desse tipo societário nesses certames.

Essa unificação jurisprudencial apresenta graves problemas. O primeiro problema centra-se no fato de existir uma alteração ao $\S 1 .{ }^{\circ}$, do artigo $3 .^{\circ}$, da Lei $8.666 / 93$, datada de 2010 , que proíbe a discriminação das cooperativas em procedimentos licitatórios e de o $\S 2 .^{\circ}$, do artigo 10, da Lei n. 12.690/2012 estatuir que as cooperativas não podem ser excluídos das licitações.

Desse modo, ante a existência de norma legal, devidamente aprovada pelo poder competente para reger tanto a licitação como as cooperativas de trabalho, tem-se que a mencionada súmula viola o princípio da legalidade, uma vez que a LINDB é enfática ao prever a lei como a principal fonte do direito. Além disso, lei posterior revoga a anterior, bem como toda a aplicação legal pretérita que seja incompatível com seu texto.

O segundo problema diz respeito ao caráter vinculante das súmulas. O TCU não pertence a nenhum dos Poderes do Estado, já que é um órgão independente e autônomo e, consequentemente, não faz parte da estrutura do Poder Judiciário. Sendo assim, a aplicação obrigatória das súmulas, conforme previsão do CPC, não alcança o TCU e, devido a isso, a uniformização jurisprudencial apontada não congrega status de lei capaz de se sobrepor à norma vigente.

O último problema vislumbrado encontra-se na parte final do texto da súmula, que diz que a proibição apresentar-se-á se a natureza do serviço a ser licitada tiver necessidade de subordinação jurídica entre o obreiro e o contratado, bem como de pessoalidade e habitualidade. Nesse caso, estar-se-á diante da burla ao concurso público, uma vez que a subordinação, a habitualidade e a pessoalidade na terceirização a tornam ilícita, acarretando uma mera simulação de prestação de serviços.

À vista disso, é necessária a imediata revogação do enunciado de Súmula n. 281, por representar uma afronta à lei e ao princípio da igualdade, que rege o procedimento licitatório, ademais de violar a previsão constitucional de fomento ao cooperativismo, tendo em vista que 
a contratação de serviços por intermédio de cooperativa de trabalho, que age dentro do escopo de seu estatuto, para ser prestado por seus associados de forma autônoma, sem qualquer vínculo de emprego, é perfeitamente legal e lícita.

\section{Bibliografia}

\section{Doutrina}

Almeida, Rachel Pereira de e KaCzUrowski, Sofia. <Cooperativismo na Previdência Social>. In: KRUEGER, Guilherme (Coord.). Comentários à Legislação das Sociedades Cooperativas - Tomo II. Belo Horizonte: Mandamentos, 2007.

CARDOne, Vanessa. Cooperativas de trabalho: legalidade e subsistência. São Paulo: Antigua, 2007.

BRASIL. OCB. Ramos do Cooperativismo. Disponível em: https://www.ocb.org. $\mathrm{br} /$ ramos. Acesso em 07.out.2020.

BRASIL. TCU. Licitações e contratos: orientações e jurisprudência do TCU. 4 ed. rev., atual. e ampl.. Brasília: TCU, Secretaria da Presidência: Senado Federal, secretaria Especial de Editoração e Publicações, 2010, p. 317.

Brasil. TCU. Súmula n. ${ }^{\circ}$ 281. Disponível em http://www.portal.tcu.gov.br. Acesso em 14.out.2020.

Gomes, Orlando; GOTTSCHALK, Elson. Curso de Direito do Trabalho. Rio de janeiro: Forense, 1990.

Krueger, Guilherme. Cooperativas de trabalho na terceirização. 2. ${ }^{a}$ ed. rev. e ampl. com comentários à Lei 12.690/2012. Belo Horizonte: Del Rey, 2014.

Martins, Sérgio Pinto. A terceirização e o Direito do Trabalho. 5 ed. rev. e ampl.. São Paulo: Atlas, 2001.

MeIRelLes, Hely Lopes. Direito Administrativo Brasileiro. 16. Ed. atual. pela Constituição de 1988, 2. tiragem. São Paulo: Editora Revista dos Tribunais, 1991.

Melto, Celso Antônio Bandeira de. Curso de Direito Administrativo. 27 ed. rev. e atual. até a Emenda Constitucional 64, de 4.2.2010. São Paulo: Editora Malheiros, 2010.

PAstorino, Roberto Jorge. Teoría General del Acto Cooperativo. Buenos Aires: INTERCOOP Editora Cooperativa, 1993.

PIMENTA, Andre Afeche. A terceirização ilícita na Administração Pública. Disponível em https://conteudojuridico.com.br/consulta/Artigos/35489/aterceirizacao-ilicita-na-administracao-publica. Acesso em: 14.out.2020.

PINHo, Diva Benevides. <Cooperativas de trabalho e emprego produtivo>. In: PINHO, Diva Benevides (organ.). Tipologia cooperativista. 3. ${ }^{a}$ ed.. vol. 4. São Paulo: CNPq, 1984

Polonio, Wilson Alves. Manual das Sociedades Cooperativas. 3. ${ }^{a}$ ed. São Paulo: Atlas, 2001. 
Polonio, Wilson Alves. Terceirização: aspectos legais, trabalhistas e tributários. São Paulo: Atlas, 2000.

SILVA, Luiz de Pinho Pedreira da. <As concepções da relação de trabalho>. In: Revista de Direito do Trabalho, vol. 127, jul-set/2007.

Silva FIlıo, Cícero Virgulino da. Cooperativas de Trabalho. São Paulo: Atlas, 2001.

SüsseKIND, Aranaldo et al.. Instituições de Direito do Trabalho. Vol. 1. 22. ${ }^{\text {a ed. }}$ atual. por Arnaldo Süssekind e João Lima Teixeira Filho. São Paulo: LTr, 2005.

TeIXeIRA Junior, Amílcar Barca; CIOTtI, Lívio Rodrigues. Cooperativas de trabalho na Administração Pública. Belo Horizonte: Mandamentos, 2003.

TeIXeIRA JúnIOR, Amílcar Barca e CIOTTI, Lívio Rodrigues. Cooperativas de Trabalho e o Termo de Conciliação Judicial AGU-MPT. Belo Horizonte: Mandamentos, 2005.

TeIXeIRA JúNIOR, Amílcar Barca e Ciottl, Lívio Rodrigues. Participação de Cooperativas em Procedimentos Licitatórios. Belo Horizonte: Mandamentos, 2002.

TeIXeIRA, Marianna Ferraz; TeIXeIRA, Marília Ferraz. (2019). «El enunciado de Súmula 602 del Tribunal Superior de Justicia de Brasil, del 22 de febrero de 2018 y la afrenta al acto cooperativo». In: Cooperativismo \& Desarrollo, 27(114), 1-18. Disponível em https://doi.org/10.16925/23824220.2019.01.01. Acesso em 14.out.2020.

\section{Legislação}

Brasil. Consolidação das Leis do Trabalho, Lei n. 5.452, de $10^{\circ}$ de maio de 1943. Disponível em http://www.planalto.gov.br. Acesso em 11.out.2020.

Brasil. Constituição de República Federativa do Brasil de 1988. Disponível em http://www.planalto.gov.br. Acesso em 13.out.2020.

BrAsIL. Decreto n. 9.507, de 21 de setembro de 2018. Disponível em http:// www. planalto.gov.br. Acesso em 13.out.2020.

Brasil. Decreto-Lei n. 22.239, de 19 de dezembro de 1932. Disponível em http://www.planalto.gov.br. Acesso em 07.out.2020.

Brasil. Decreto-Lei n. 200, de 25 de fevereiro de 1967. Disponível em http:// www.planalto.gov.br. Acesso em 13.out.2020.

Brasil. Lei n. 5.764, de 16 de dezembro de 1971. Disponível em http://www. planalto.gov.br. Acesso em 11.out.2020.

BrASIL. Lei n. 8.666, de 21 de junho de 1993. Disponível em http://www. planalto.gov.br. Acesso em 13.out.2020.

BrasIL. Lei n. 12.690, de 19 de julho de 2012. Disponível em http://www. planalto.gov.br. Acesso em 07.out.2020.

BRASIL. TCU. Regimento Interno. Disponível em http://www.portal.tcu.gov.br. Acesso em 14.out.2020. 


\section{Derechos de autor}

http://dec.revistas.deusto.es/

La revista Deusto Estudios Cooperativos es una revista de acceso abierto lo que significa que es de libre acceso en su integridad inmediatamente después de la publicación de cada número. Se permite su lectura, la búsqueda, descarga, distribución y reutilización legal en cualquier tipo de soporte sólo para fines no comerciales y según lo previsto por la ley; sin la previa autorización de la Editorial (Universidad de Deusto) o el autor, siempre que la obra original sea debidamente citada (número, año, páginas y DOI si procede) y cualquier cambio en el original esté claramente indicado.

\section{Copyright}

The Deusto Journal of Cooperative Studies is an Open Access journal which means that it is free for full and immediate access, reading, search, download, distribution, and lawful reuse in any medium only for non-commercial purposes, without prior permission from the Publisher or the author; provided the original work is properly cited and any changes to the original are clearly indicated. 